\title{
MAKNA LIRIK LAGU "PAPURIKA HANA GA SAITARA HARETA SORA NI TANE WO MAKOU" DALAM LAGU PAPURIKA
}

\author{
P.R. Megantari ${ }^{1}$, N.P.W.T. Ariantari ${ }^{2}$, M.M.S. Dewi ${ }^{3}$ \\ ${ }^{123}$ Jurusan Pendidikan Bahasa Jepang, Universitas Pendidikan Ganesha, Singaraja \\ e-mail: ratihmega1208@gmail.com, windatya44@gmail.com, martasarid90@gmail.com
}

\begin{abstract}
Abstrak
Artikel ini dibuat untuk menganalisis makna lirik lagu "Papurika hana ga saitara, hareta sora ni tane wo makou" dalam lagu "Papurika" dengan analisis makna intrinsic dan ekstrinsik lagu tersebut. Lagu Paprika tersebut merupakan sebuah lagu yang dirilis oleh Kenshi Yonezu pada tahun 2018 yang menjadi sebuah trending dengan jumlah penonton 260 juta orang dan dirilis secara digital pada 2 Desember 2019. Kemudian lagu tersebut dinyanyikan oleh grup anak-anak yaitu Foorin. Lagu ini juga digunakan sebagai lagu tema untuk Tokyo Olympics mendatang. Seluruh royalty dari single ini akan disumbangkan ke Japan Sport Council untuk pembinaan atlet generasi yang selanjutnya.
\end{abstract}

Kata kunci: Impian dan Harapan, Keadaan yang berubah, Papurika hana ga saitara hareta sora ni tane wo makou, Lagu

\section{Pendahuluan}

Lagu Paprika ialah lagu yang bertemakan harapan/mimpi seseorang yang berada dalam situasi atau keadaan yang terus berubah. Lagu ini diciptakan oleh Kenshi Ynezu yang kemudian discover oleh grup vocal anak-anak yaitu Foorin. Nama grup Foorin tersebut dinamai langsung oleh Kenshi Yonezu karena melihat anak-anak tersebut seperti perkusi angin (Furin) yang ada di Jepang. Dalam lagu ini terdapat lirik "Papurika hana ga saitara, hareta sora ni tane wo makou" yang akan kami teliti dari segi makna berdasarkan teori Triangle of Meaning oleh Charles Sanders Pierce dan menganalisis unsur intrinsik dan ekstrinsik. Berdasarkan latar belakang tersebut, rumusan masalah yang didapatkan yaitu sebagai berikut :

a. Bagaimana makna intrinsik dan ekstrinsik dari lagu tersebut ?

b. Bagaimana analisa makna lirik lagu "Papurika hana ga saitara, hareta sora ni tane wo makou" berdasarkan teori Triangle of Meaning oleh Charles Sanders Pierce?

\section{Metode}

Penelitian yang dilakukan bersifat deskriptif kualitatif. Tujuan dari dilaksanakannya penelitian ini adalah untuk mencari dan mengetahui makna dari lirik lagu "Papurika hana ga saitara, hareta sora ni tane wo makou" yang terdapat pada lagu "Paprika" dengan unsur instrinsik dan ekstrinsik lagu dan menggunakan teori Triangle of Meaning oleh Charles Sanders Pierce. Unsur instrinsik didapatkan memlaui penerjemahan secara harafiah lagu Paprika dan unsur ekstrinsik didapatkan melalui kaitan antara peristiwa yang menjadi alasan atau penyebab lagu tersebut diciptakan. Melalui hasil analisa unsur instrinsik dan ekstrinsik tersebut, peniliti menarik hasil makna lirik lagu "Papurika hana ga saitara, hareta sora ni tane wo makou" dalam lagu "Paprika"

Dalam teori tersebut Peirce menyebutkan bahwa semiotika memungkinkan kita berpikir mengenai tanda - tanda yang berhubungan dengan orang lain dan memberikan makna pada apa yang ditampilkan oleh alam semesta. Objek - objek yang menyerupai tersebut diikatkan dengan tanda-tanda dan memiliki hubungan - akibat. Penganut teori Pierce bertugas untuk menemukan koherensi dan menyaring hal - hal yang penting, agar teori yang bersifat umum tersebut dapat diterapkan dalam segala macam tanda dengan menggunakan konsep - konsep baru. Analisis semiotika menurut Charles Sanders Pierce terdiri dari tiga aspek penting yang sering disebut dengan Triangle of Meaning ketiga aspek tersebut adalah :

a. Tanda 
Dalam kajian semiotik menurut Pearce, disebutkan bahwa tanda adalah konsep utama yang akan digunakan sebagai bahan analisis.

b. Simbol (Object)

Tanda dijadikan sumber acuan melalui kesepakatan atau persetujuan

c. Interpretasi.

Konsep pemikiran yang bersumber dari orang yang menggunakan tanda dan menurunkannya kedalam suatu makna tertentu, yang merujuk ke suatu tanda.

\section{Hasil dan Pembahasan}

\section{a. Makna Instrinsik lagu Paprika}

パプリカ

曲りくねり はしやいだ道

青葉の森で駆け回る

遊びまわり 日差しの街

誰かが呼んでいる

夏が来る 影が立つ あなたに会いたい

見つけたのはいちばん星

明日も晴れるかな

パプリカ 花が咲いたら

晴れた空に種を蒔こう

ハレルヤ 夢を描いたなら

心遊ばせあなたにとどけ

雨に燻り 月は陰り

木陰で泣いてたのは誰

一人一人 慰めるように

誰かが呼んでいる

喜びを数えたら あなたでいっぱい

帰り道を照らしたのは

思い出のかげぼうし

パプリカ 花が咲いたら

晴れた空に種を蒔こう

ハレルヤ 夢を描いたなら

心遊ばせあなたにとどけ

会いに行くよ 並木を抜けて

歌を歌って

手にはいっぱいの 花を抱えて

らるらりら

会いに行くよ 並木を抜けて

歌を歌って

手にはいっぱいの 花を抱えて

らるらりら

パプリカ 花が咲いたら 
晴れた空に種を蒔こう
ハレルヤ 夢を描いたなら
心遊ばせあなたにとどけ
かかと弾ませこの指とまれ

Makna Intrinsik dari lagu "Papurika hana ga saitara, hareta sora ni tane wo makou" dalam lagu tersebut ialah :

1. Tema : Semangat dengan harapan dan impian yang dimiliki

2. Nada : Nada lagu ini ceria dan semangat yang membuat orang lain memiliki semangat kembali untuk meraih mimpinya

3. Diksi : Diksi yang digunakan adalah untuk mengungkapkan perasaan penulis dan untuk membuat orang lain ikut merasakan.

4. Amanat : Raihlah mimpi dan harapan walaupun berada dalam situasi yang terus berubah (yang tidak bisa diprediksi)

\section{b. Makna Ekstrinsik Lagu Paprika}

Lagu ini diciptakan oleh Kenshi Yonezu pada tahun 2018 dan mendapatkan views sebanyak 260 juta orang sehingga menjadikan lagu ini trending pada saat itu. Versi digital lagu ini dirilis pada 2 Desember 2019. Lagu ini menjadi meroket kembali setelah grup vocal anak-anak meng-cover lagu ini kembali. Grup vocal anak-anak ini diberikan nama Foorin karena anak-anak tersebut memiliki tarian yang ekspresif seperti perkusi angin (furin) yang ada di Jepang. Selain discover oleh grup vocal anak-anak di Jepang, lagu ini juga di cover oleh Foorin Tim E yang dinyanyikan dalam versi bahasa inggris. Lagu ini juga digunakan sebagai lagu tema untuk Tokyo Olympics 2020 yang akan datang. Seluruh hasil royalty dari lagu tersebut akan disumbangkan ke Japan Sport Council sebagai pembinaan untuk atletatlet pada generasi selanjutnya. Single NHK ini memiliki nuansa lagu yang ceria dan dapat memberikan semangat bagi yang mendengarnya.

\section{c. Makna lirik "Papurika hana ga saitara, hareta sora ni tane wo makou" berdasarkan unsur intrinsik, ekstrinsik dan teori Triangle of Meaning}

Dari unsur intrinsiknya, lirik "Papurika hana ga saitara, hareta sora ni tane wo makou" dianalogikan sebagai sebuah bunga yang mekar dan beterbangan di udara. Bunga paprika yang diibaratkan sebagai suatu momentum untuk manusia agar dapat bangkit kembali dan meneruskan impiannya. Menurut teori Triangle of Meaning yang didalamnya terdapat tanda, objek dan intepretan dapat dijabarkan yaitu tanda yang didapatkan ialah momentum seseorang untuk bangkit dan meneruskan harapan serta mimpinya. Objek yang digunakan adalah bunga paprika yang mekar dan beterbangan di udara. Interpretan yang didapatkan ialah harapan itu pasti akan dicapai meskipun dalam situasi yang terus berubah dan tidak dapat diprediksi oleh siapapun. Maka dari itu dapat ditarik makna yaitu sebagai lambang sebuah harapan dan impian seseorang dalam situasi yang berubah-ubah dan berusaha untuk menggapainya.

\section{Simpulan dan Saran}

Berdasarkan hasil analisis, dapat disimpulkan bahwa makna dari lirik lagu "Papurika hana ga saitara, hareta sora ni tane wo makou" yang terdapat pada lagu Paprika karya Kenshi Yonezu berdasarkan makna intrinsik, ekstrinsik dan teori Triangle of Meaning ialah sebagai lambing bahwa seseorang yang memiliki harapan dan mimpi akan terus mengejar hingga dapat meraihnya walaupun berada dalam suatu situasi yang tidak dapat diprediksi.

\section{Daftar Pustaka}

kaorinusantara.or.id. Intip video dari lagu paprika karya kenshi yonezu versi bahasa inggris. 26 Desember 2019. https://www.kaorinusantara.or.id/newsline/141960/intip-video-klipdari-lagu-paprika-karya-kenshi-yonezu-versi-bahasa-inggris 
Wibowo, Hendra Wahyu Hadi. 2015. Analisis Struktur Dan Makna Lirik Lagu Karya Group Band Power Metal Dalam Kajian Aspek Sosial.

Tommy, Darmawi. 2016. Konsep Kesedihan dalam Lirik Lagu Hoshizora dan Daybreak's Bell Karya L’Arc-En-Ciel. ラルク・アン・シエルの[星空] と[デイブレイクベル]におけ る悲しみの概念. PhD diss., Universitas Darma Persada. 